\title{
1-Methylcyclopropene Improves Postharvest Performances and Sensorial Attributes of Annurca-Type Apples Exposed to the Traditional Reddening in Open-Field Melaio
}

\author{
Maria Tiziana Lisanti ${ }^{1, *}$, Alessandro Mataffo ${ }^{1} \mathbb{D}$, Pasquale Scognamiglio ${ }^{1}$, Maurizio Teobaldelli ${ }^{1}$ (D),

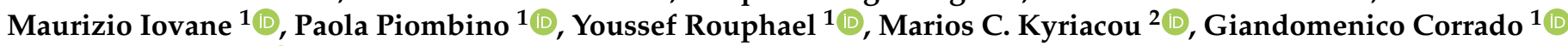 \\ and Boris Basile ${ }^{1, * \mathbb{D}}$ \\ 1 Department of Agricultural Sciences, University of Naples Federico II, 80055 Portici, Italy; \\ alessandro.mataffo@unina.it (A.M.); pasquale.scognamiglio2@unina.it (P.S.); \\ maurizio.teobaldelli@gmail.com (M.T.); maurizio.iovane@unina.it (M.I.); paola.piombino@unina.it (P.P.); \\ youssef.rouphael@unina.it (Y.R.); giandomenico.corrado@unina.it (G.C.) \\ 2 Agricultural Research Institute, P.O. Box 22016, Nicosia 1516, Cyprus; m.kyriacou@ari.gov.cy \\ * Correspondence: mariatiziana.lisanti@unina.it (M.T.L.); boris.basile@unina.it (B.B.)
}

Citation: Lisanti, M.T.; Mataffo, A.; Scognamiglio, P.; Teobaldelli, M.; Iovane, M.; Piombino, P.; Rouphael, Y.; Kyriacou, M.C.; Corrado, G.; Basile, B. 1-Methylcyclopropene Improves Postharvest Performances and Sensorial Attributes of

Annurca-Type Apples Exposed to the Traditional Reddening in Open-Field Melaio. Agronomy 2021, 11, 1056. https: / / doi.org/10.3390/ agronomy11061056

Academic Editors: Giorgia Liguori and Noemi Tel-Zur

Received: 21 April 2021

Accepted: 19 May 2021

Published: 24 May 2021

Publisher's Note: MDPI stays neutral with regard to jurisdictional claims in published maps and institutional affiliations.

Copyright: (C) 2021 by the authors Licensee MDPI, Basel, Switzerland. This article is an open access article distributed under the terms and conditions of the Creative Commons Attribution (CC BY) license (https:// creativecommons.org/licenses/by/ $4.0 /)$.
Abstract: The Annurca type is an historical Italian apple fruit probably native to the Campania region. These fruits are harvested before a full maturity stage and go through an open-field reddening process. Products based on 1-methylcyclopropene (1-MCP) are widely used in postharvest to improve apple quality and avoid disorders in controlled atmosphere. In this work, we tested the impact of 1-MCP in the traditional reddening system of Annurca type by analyzing three postharvest strategies, namely, fruits exposed for ten days to the traditional reddening and then cold-stored (RDG treatment); fruits treated in postharvest with 1-MCP and then cold-stored (MCP treatment); fruits treated in postharvest with 1-MCP, exposed for ten days to the open-field reddening and then cold-stored (MCP + RDG treatment). Using a full factorial design, we measured main physical and compositional traits and described the properties of the products by consumer testing at two storage times. The MCP + RDG treatment provided the most valuable results, by positively affecting fruit flesh firmness and several sensorial attributes (e.g., hardness, crunchiness, juiciness, sweetness), including a reduction of the mealiness. At the end of the cold-storage, MCP + RDG apples scored a higher consumer's overall liking. The work demonstrated that the 1-MCP technology can be integrated into a traditional open-field postharvest process to improve fruit quality and, potentially, to extend the shelf life of Annurca apples.

Keywords: $1-\mathrm{MCP}$; Malus $\times$ domestica; fruit color; consumer test; food quality; landrace

\section{Introduction}

With a total production of 2.4 million tons, Italy is the sixth largest apple producer in the world [1]. Although Italy has a rich indigenous collection of varieties, virtually all the germplasm is of foreign origin, a result of two major waves of introduction. The first occurred in the 18th century, with the Middle European-centered development of scientific pomology and of apple selection programs. The second began after the Second World War and was dominated by the germplasm originating from USA and, later, also from Oceania. Especially after Second World War, the introduction of new material associated with the adoption of pre- and postharvest management techniques (in terms of orchard layout, training systems and market standards) that uniformly characterize the current intensive apple production in the world.

Among the rich and historical Italian fruit germplasm, the cultivar "Annurca" and its clonal derivative "Rossa del Sud" are arguably the most important varieties. The cultural and gastronomic value of the Annurca-type apples has been recognized by an EU Protected 
Geographical Indication (PGI) since 2006. The fruits produced under the PGI protocol are commercialized as "Melannurca Campana" apples and can derive from the "Annurca" and "Rossa del Sud". These varieties were almost extinct in the 1970s, but since then, they have experienced a growing market success, today representing $5 \%$ of the Italian apple production and around $80 \%$ of that from the Campania region [2,3]. The reasons of this success are the high firmness, characteristic taste, relatively small size and functional quality attributes of the fruits [4,5], as well as the growing consumer appreciation for traditional, indigenous food [6]. A distinctive feature of the Annurca production system is that apples are handpicked before maturity (before skin red color is fully developed), at the end of the summer, to avoid fruit drop. This is an unavoidable consequence of the short fruit stem, usual in old varieties that have not been involved in formal breeding. The Annurca-type apples go through a traditional, unique postharvest management for reddening. In open fields, apples are lined up on a bed made of woodchips or straw over the soil surface, in a structure traditionally called "melaio" (from "mela", the Italian word for apple). Apples are moistened as necessary and protected by horizontal shading nets to avoid excessive exposure to light and possible sunburns. When the skin of the exposed side turns red, fruits are manually rolled to provide a uniform red color to the apple, a process that lasts up to 30 days depending also on weather conditions [7]. During reddening, fruits develop their distinctive aroma because of an increase in esters and alcohols, as well as of pentyl esters and cultivar-specific compounds such as $\delta$-octalactone $[8,9]$. The postharvest reddening in the uncontrolled open-field conditions also represents one of the main problems that growers face for the commercial production. Reddening in melaio associates with an overall yield loss, due to fruit transpiration and respiration. Moreover, part of the production may become unsuitable for marketing because of a loss of flesh firmness, mealiness, physiological disorders and pathogen attack [9]. All this prompts for technologies that should allow a tighter control of fruit storage, with the main aim of extending its length without significantly altering the sensory standards of this premium apple.

The 1-methylcyclopropene (1-MCP) is one of the most employed tools by storage operators to manage fruit quality in postharvest. 1-MCP is a gaseous cyclic olefin, able to extend storage and shelf-life of both climacteric and not climacteric fruits [10,11]. The 1-MCP inhibits ethylene biosynthesis through competitive binding to the ethylene receptors [12-15], slowing fruit senescence. The potential application of 1-MCP has attracted large interest in horticulture, but nowadays, its most successful commercial use is on the apple [16-21]. Nonetheless, considerable variation in postharvest practices exists among cultivars, although information is available only on contemporary varieties $[19,22]$. These studies also imply that the successful deployment of 1-MCP in the apple industry requires understanding of these genotype-specific responses. This is expected to be relevant because it has been shown that the "Melannurca Campana" varieties ("Rossa del Sud" and "Annurca") have a distinct genetic profile, also compared to other traditional apple cultivars [23].

Because of its recent economic success, the "Melannurca Campana" postharvest is still managed only with traditional techniques. Little efforts have been performed to investigate factors that, when correctly integrated in the traditional production system, can improve fruit quality and return for producers. PGI "Melannurca Campana" apples are harvested with a maturity that is potentially suitable for postharvest management in controlled atmosphere. Therefore, in this work, we tested the usefulness and impact of 1-MCP in the traditional reddening system by studying the effect of three different postharvest management schemes. Since sensory attributes are not always predictable by instrumental measures [24,25], we adapted a combined approach measuring the main apple's chemical and physical properties as well as the characteristics and performance of the produce in a consumer test. 


\section{Materials and Methods}

\subsection{Experimental Site and Plant Material}

The study was conducted in a 5 ha commercial apple (Malus $\times$ domestica Borkh) orchard, located in Tora e Piccilli (Caserta, Italy) in 2017-2018. Fruits were picked from 7year-old apple trees of the cultivar "Rossa del Sud", grafted onto "M9" rootstock. The trees were spaced $4.0 \mathrm{~m} \times 1.5 \mathrm{~m}$, trained to a palmette system to form hedgerows with an east-west row orientation. The fruit of 30 trees was harvested manually on 25 September 2017, when fruits reached a soluble solids content around $11.5^{\circ}$ Brix, as indicated by the production protocol "Melannurca Campana" PGI [26]. This occurred when fruits were not fully mature, and the extension of the red cover color was between $30-50 \%$ of the skin surface.

\subsection{Experimental Design}

The experimental design compared three treatments corresponding to the following three postharvest fruit managements: (1) a commercial control (hereafter indicated as RDG), where fruits, once harvested, went through a 10-day long reddening in the open field (melaio) and were then cold-stored; (2) fruits, once harvested, were treated with a commercial product generating gaseous 1-MCP (Smartfresh ${ }^{\mathrm{TM}}$, Agrofresh, Philadelfia, PA, USA) applied at a concentration of $55.5 \mathrm{mg} / \mathrm{m}^{3}$ and were then cold-stored (MCP treatment); (3) fruits, once harvested, were treated with 1-MCP (as described for the MCP treatment) and were then cold-stored for one month; after that, fruits were exposed to reddening in the open field (melaio) for ten days and then cold-stored again (RDG+MCP treatment). The 1-MCP was applied by the fumigant method in a commercial air-tight cold room with a temperature set at $2.5^{\circ} \mathrm{C}$ for $24 \mathrm{~h}$ (apples were pre-cooled before 1-MCP application). Cold storage was done in a commercial cold room (set at a temperature of $1{ }^{\circ} \mathrm{C}$ and a relative humidity of $90 \%$ and equipped with an ethylene extractor). During the reddening stage of RDG apples, average minimum, maximum and mean air temperatures were 9.9, 21.5 and $15.4{ }^{\circ} \mathrm{C}$, respectively. The apples were analyzed on the following two dates: on 16 November 2017 when the apples of the RDG + MCP treatment finished the reddening stage to be moved to the cold-storage room (hereinafter, Storage Time 1, ST1) and after three months, on 22 February 2018 (hereinafter, ST2). On each sampling date (ST1 and ST2), a total of 100 apples with a 65-85 mm caliber were sampled for each treatment to carry out composition analyses, photographic analyses of skin and consumer sensory tests.

\subsection{Analysis of Fruit Skin Colour}

On each sampling date, fruit skin color was measured on 20 fruits per treatment using an image analysis approach [27]. A single apple was placed inside a lightbox with a uniform and all-surrounding diffuse light provided by three $60 \mathrm{~W}$ lamps and then photographed on the two opposite sides with a digital camera (D3100; Nikon, Tokyo, Japan) from a fixed distance $(40 \mathrm{~cm})$. Each 24 bit digital photo (in RAW format, sRGB color space), consisting of $3 \times 8$ bit channels was processed in Photoshop CS6 (Adobe; San Jose, CA, USA). The photo was cropped to match the apple silhouette with the outer edges of the image, then, after removing the background, the image was saved in tagged image file format (TIFF). All images were processed automatically using the Scion Image software, and digital number (DN) values were measured in each photo as follows: automatic creation in the central part of the photo of a circular selection window with dimensions proportional to the overall size of the photo; pixel analysis, for each RGB channel, within the selected area; automatic saving in a comma-separated values (csv) file of the data (size of the selected area; maximum, minimum, average and standard deviation of the DN) relative to the analyzed area. The csv files were analyzed, and the values of the DNs related to the RGB channels were used to calculate the corresponding $\mathrm{L}^{*}, \mathrm{a}^{*}$ and $\mathrm{b}^{*}$ coordinates 
according to the CIELab standard [28]. Finally, the value of the psychometric tint angle $h$ (hue-angle) was estimated as:

$$
\mathrm{h}=\arctan \left(\frac{\mathrm{b}^{*}}{\mathrm{a}^{*}}\right) \text { with } 0^{\circ} \leq \mathrm{h} \leq 360^{\circ}
$$

where $\mathrm{a}^{*}$ and $\mathrm{b}^{*}$ are the corresponding coordinates of the CIELab standard.

To measure the change in visual perception induced by the treatments in fruit skin color, the color difference $\Delta_{a b}^{*}$ between couples of treatments was calculated as follows:

$$
\Delta E_{a b}^{*}=\sqrt{\left(L_{2}^{*}-L_{1}^{*}\right)^{2}+\left(a_{2}^{*}-a_{1}^{*}\right)^{2}+\left(b_{2}^{*}-b_{1}^{*}\right)^{2}}
$$

where $\Delta E_{a b}^{*}$ is the colour difference, $L_{2}^{*}, a_{2}^{*}, b_{2}^{*}$ and $L_{1}^{*}, a_{1}^{*}, b_{1}^{*}$ are the CIELab coordinates of the two treatments compared (treatment 2 vs. treatment 1 ), respectively. We defined the following thresholds for human visual perception in color differences: $\Delta E_{a b}^{*} \leq 1.0$ : not perceptible by human eyes; $1.0<\Delta E_{a b}^{*} \leq 2.0$ : perceptible through close observation; $2.0<\Delta E_{a b}^{*} \leq 10.0$ : perceptible at a glance; $11.0<\Delta E_{a b}^{*} \leq 49.0$ : colors are more similar than opposite; $\Delta E_{a b}^{*}=100$ : colors are exact opposite.

\subsection{Analysis of Apple Starch Content}

Fruit starch content was evaluated using a starch pattern index (SPI) following a previously described methodology [29]. Briefly, ten apples per treatment were transversally cut in half at the equatorial region, and iodine solution was applied to the cut surface of one of the halves. After one minute, the SPI was visually estimated using as reference the Cornell Starch-Iodine Index ripeness scale of 1-8 [29], where 1 and 8, respectively, indicates that 100 and $0 \%$ of the surface cut is covered by the starch-iodine complex stain. The adopted SPI has been shown to effectively describe the changes in starch concentration in the fruits of different apple cultivars [30].

\subsection{Firmness, Total Soluble Solids Content, $\mathrm{pH}$ and Titratable Acidity}

At each sampling date, 30 fruits per treatment were used to measure pulp firmness. Firmness was measured at the equator at two opposite spots (hence, $n=60$ ), where the skin of the fruit was previously removed, using a digital penetrometer (model 53205, TR, Forlì, Italy) equipped with an $8 \mathrm{~mm}$ tip. Total soluble solids content was measured on the juice of 30 fruits, by a digital table refractometer (HI96811; Hanna instruments, Padova, Italy). On a sample of 10 fruits per treatment, the $\mathrm{pH}$ was measured by a digital $\mathrm{pH}$-meter (CLB22; Crison Instruments, Alella, Spain) on a $2.5 \mathrm{~mL}$ solution of juice diluted with $7.5 \mathrm{~mL}$ of distilled water. Subsequently, the titratable acidity was measured by titrating the same solution with $0.1 \mathrm{~N}$ sodium hydroxide until reaching $\mathrm{pH} 8.1(n=10)$, and the results were expressed as $\mathrm{g} / \mathrm{L}$ of malic acid.

\subsection{Consumer Sensory Tests}

On the sampling dates (ST1 and ST2), consumer tests were performed at the Department of Agricultural Sciences, University of Napoli Federico II (Italy) and involved 100 consumers each. Data on consumption of apples, age and gender were collected. Criteria for inclusion in the panel were absence of allergies to apples and being a regular apple consumer. On each sampling date, the sensory tests took place within the same morning of sampling and lasted three hours, starting from 10:00 a.m. Each session was divided in sub-sessions attended by ten consumers each. All the treatments were tested in each session, and each consumer tested all the treatments. Fruit samples were prepared by cutting two longitudinal slices about $30 \mathrm{~mm}$ wide at the outer edge, with the skin left on. To avoid pulp oxidation (browning), sample preparation took place at the time of testing. The presentation of samples within each sampling date was balanced for order and carryover effects. Each consumer received a tray with three disposable plastic cups containing the samples, coded with random three-digit codes. After an explanatory introduction, 
consumers were asked to taste each sample individually and to rate their overall liking by using 9 -point hedonic numerical category scales $(1=$ extremely dislike, $9=$ extremely like, with $5=$ neither like nor dislike). They were also asked to rate the following attributes: hardness, crunchiness, juiciness, mealiness, sweetness, sourness and aroma intensity using a 9-points scale anchored with verbal labels (from $1=$ very low to $9=$ very high, with $5=$ medium). At the end of the test, consumers were immediately invited to write a brief comment if they wished to do so.

\subsection{Statistical Analysis}

The effect of the different treatments on the measured parameters was assessed by two-way ANOVA followed by Duncan's post hoc test for the separation of the means. Statistically significant differences were defined as ${ }^{*} p<0.05,{ }^{* *} p<0.01$ and ${ }^{* * *} p<0.001$. These analyses were performed with SPSS 26 (IBM; Arkon, NY, USA). A correlogram representing the Pearson correlation coefficient $(n=6)$ matrix between the apples' physicochemical features and sensory attributes was built using RStudio (Rstudio, Boston, MA, USA).

\section{Results}

\subsection{Fruit Skin Colour}

The development of the red color is the aimed visible alteration in melaio, yet color variation in postharvest was related to all the different parameters (Table 1). The main effect of the storage time (ST) on lightness was a significant reduction. This trait almost halved from ST1 to ST2, resulting in the typical matte appearance of the Annurca-type apples (Supplementary Figure S1). The ST was also associated with increased redness $(+33.0 \%)$ and yellowness $(+56.7 \%)$. These parameters were also influenced by the postharvest treatment (T). Overall, the MCP management did not only preserve better the lightness but associated to a higher redness and yellowness, followed by the MCP + RDG treatment.

Table 1. Effect postharvest management treatment (T), storage time (ST) and $\mathrm{S} \times \mathrm{T}$ interaction on the skin color of the apples.

\begin{tabular}{|c|c|c|c|c|}
\hline Source of Variation & $\mathbf{L}^{*}$ & $a^{*}$ & $\mathbf{b}^{*}$ & Hue Angle \\
\hline \multicolumn{5}{|l|}{ Treatment (T) } \\
\hline RGD & $28.9 \pm 1.2 \mathrm{c}$ & $21.6 \pm 0.4 \mathrm{c}$ & $12.7 \pm 0.4 \mathrm{c}$ & $29.8 \pm 0.5 b$ \\
\hline $\mathrm{MCP}$ & $35.5 \pm 1.2 \mathrm{a}$ & $25.4 \pm 0.7 \mathrm{a}$ & $19.4 \pm 0.8 \mathrm{a}$ & $36.5 \pm 1.2 \mathrm{a}$ \\
\hline $\mathrm{MCP}+\mathrm{RDG}$ & $30.5 \pm 1.2 b$ & $23.9 \pm 0.5 b$ & $14.3 \pm 0.4 \mathrm{~b}$ & $30.4 \pm 0.4 b$ \\
\hline Significance & $* * *$ & $* * *$ & $* * *$ & $* * *$ \\
\hline \multicolumn{5}{|l|}{ Storage Time (ST) } \\
\hline ST1 & $41.6 \pm 0.4 a$ & $20.3 \pm 0.3 b$ & $12.0 \pm 0.3 b$ & $30.3 \pm 0.7 \mathrm{~b}$ \\
\hline ST2 & $21.7 \pm 0.5 b$ & $27.0 \pm 0.4 \mathrm{a}$ & $18.8 \pm 0.6 \mathrm{a}$ & $34.2 \pm 0.7 \mathrm{a}$ \\
\hline Significance & $* * *$ & $* * *$ & $* * *$ & $* * *$ \\
\hline $\mathrm{T} \times \mathrm{ST}$ & n.s. & $* *$ & $* * *$ & n.s. \\
\hline
\end{tabular}

n.s., $,{ }^{* * *}, * * *$ non-significant or significant at $p \leq 0.05,0.01$ and 0.001 , respectively.

In absolute terms, the highest color difference in pairwise comparisons at both ST1 and ST2 was between apples of the MCP and RDG ( $\left.\Delta E_{a b S T 1}^{*}: 7.48 ; \Delta E_{a b S T 2}^{*}: 13.03\right)$, while the lowest was between MCP + RDG and RDG $\left(\Delta E_{a b S T 1}^{*}: 3.52 ; \Delta E_{a b S T 2}^{*}: 3.23\right)$. The color difference between apples at ST1 and ST2 differed very little among treatments $\left(\Delta E_{a b R D G}^{*}: 21.66\right.$; $\left.\Delta E_{a b \mathrm{MCP}}^{*}: 22.44 ; \Delta E_{a b \mathrm{MCP}}^{*}+\mathrm{RDG}: 22.56\right)$. A significant $\mathrm{T} \times \mathrm{ST}$ interaction was present only for the chromatic components $\left(a^{*}\right.$ and $\left.b^{*}\right)$. The higher redness of the MCP-treated apples was significant only at ST2, and at the first sampling time, the redness of the apples following the MCP and MCP + RDG treatments was not different (Figure 1). Similarly, the maximum relative increase in yellowness between ST1 and ST2 was recorded for the $\mathrm{MCP}$ treatment, but at the later time point, $\mathrm{b}^{*}$ did not significantly differ between $\mathrm{MCP}+$ RDG and RDG. 


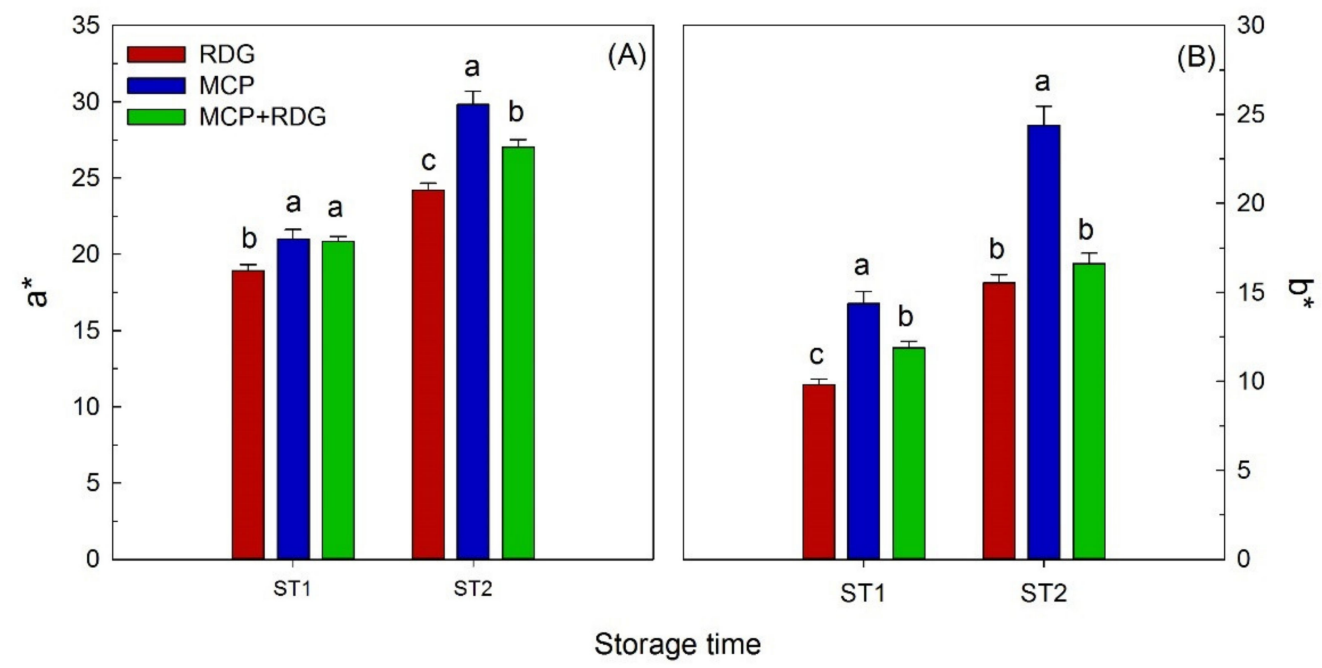

Figure 1. Chromatic components (A) $a^{*},(\mathbf{B}) b^{*}$ measured at two storage times (ST1 and ST2) on the fruit skin of apples exposed to the three postharvest management treatments, RDG (standard reddening process), MCP (apples treated with 1-MCP, without the reddening process) and MCP + RDG (apples treated with 1-MCP and with the reddening process). For each sampling time, different letters indicate statistically different value $(p \leq 0.05)$.

\subsection{Fruit Flesh Firmness and Fruit Composition}

Apples at the different STs did not differ in firmness, while the postharvest management had a significant influence (Table 2).

Table 2. Effect of the postharvest management treatment $(\mathrm{T})$, storage time $(\mathrm{ST})$ and $\mathrm{T} \times \mathrm{S}$ interaction on apple flesh firmness, soluble solids content (CSS), $\mathrm{pH}$, titratable acidity (TA), SSC/TA ratio and starch pattern index (SPI).

\begin{tabular}{|c|c|c|c|c|c|c|}
\hline $\begin{array}{l}\text { Source of } \\
\text { Variation }\end{array}$ & $\begin{array}{c}\text { Flesh Firmness } \\
\text { (N) }\end{array}$ & SSC $\left({ }^{\circ}\right.$ Brix $)$ & $\mathrm{pH}$ & $\begin{array}{c}\text { TA } \\
\text { (g/L Malic Acid) }\end{array}$ & SSC/TA & SPI \\
\hline \multicolumn{7}{|l|}{ Treatment (T) } \\
\hline RGD & $37.8 \pm 0.8 b$ & $14.9 \pm 0.1 \mathrm{a}$ & $3.48 \pm 0.03$ & $5.8 \pm 0.2 b$ & $2.60 \pm 0.09 a$ & $7.35 \pm 0.11 a$ \\
\hline $\mathrm{MCP}$ & $53.2 \pm 1.1 \mathrm{a}$ & $14.3 \pm 0.1 b$ & $3.41 \pm 0.04$ & $7.4 \pm 0.2 \mathrm{a}$ & $1.97 \pm 0.07 \mathrm{~b}$ & $5.35 \pm 0.45 b$ \\
\hline $\mathrm{MCP}+\mathrm{RDG}$ & $50.6 \pm 0.9 a$ & $14.9 \pm 0.1 \mathrm{a}$ & $3.46 \pm 0.03$ & $7.3 \pm 0.3 a$ & $2.09 \pm 0.10 b$ & $7.45 \pm 0.14 a$ \\
\hline Significance & $* * *$ & $* * *$ & n.s. & $* * *$ & $* * *$ & $* * *$ \\
\hline \multicolumn{7}{|l|}{$\begin{array}{l}\text { Storage Time } \\
\text { (ST) }\end{array}$} \\
\hline ST1 & $48.0 \pm 1.2$ & $14.4 \pm 0.1 b$ & $3.36 \pm 0.03$ & $7.8 \pm 0.2 \mathrm{a}$ & $2.00 \pm 0.08 b$ & $5.83 \pm 0.32 b$ \\
\hline ST2 & $46.4 \pm 0.9$ & $15.0 \pm 0.1 \mathrm{a}$ & $3.54 \pm 0.02$ & $6.3 \pm 0.2 b$ & $2.44 \pm 0.07 \mathrm{a}$ & $7.60 \pm 0.09 a$ \\
\hline Significance & n.s. & $* * *$ & $* * *$ & $* * *$ & $* * *$ & $* * *$ \\
\hline $\mathrm{T} \times \mathrm{ST}$ & n.s. & n.s. & n.s. & $* * *$ & * & $* * *$ \\
\hline
\end{tabular}

n.s., ${ }^{*}, * * * * *$ non-significant or significant at $p \leq 0.05,0.01$ and 0.001 , respectively.

Specifically, apples that underwent the two treatments that included MCP were firmer than RDG apples. Although differences were more limited, an opposite trend was observed for the SSC, which increased with the storage time but was significantly lower in apples of the MCP treatments. The ST had a significant effect on the $\mathrm{pH}$ of the juice, which was also higher at ST2 because an overall reduction of the titratable acidity. However, the correlation between $\mathrm{pH}$ and TA was affected by the postharvest treatment, with both MCP and $\mathrm{MCP}+$ RDG having higher (around + 26\%) TA, compared to the RDG apples, but similar $\mathrm{pH}$ values of the juice. Moreover, there were combined effects of the two factors on the TA. Specifically, the high TA values were recorded for apples of the MCP + RDG (respectively, MCP) treatment at ST1 (resp., at ST2). The SSC to TA ratio was also significantly affected by the two factors and their interaction, with apples of the RGD having higher values because of the lower titratable acidity. However, at the second time point, the SSC/TA ratio of the apples of the MCP + RDG treatment was not significantly different from those of the 
other treatments (Figure 2). The starch pattern index (SPI) increased (+30\%) during the storage time, but differently from the other parameters, both treatments that included a stage in melaio (i.e., RGD and the MCP + RGD) had the highest starch content. Although at ST2, the SPI value is lower for MCP apples, a significant factor interaction is noteworthy, with the time in storage having the highest relative effect (+101\%) for the MCP treatment, resulting in a limited significant difference at ST2 among treatments (Figure 2).

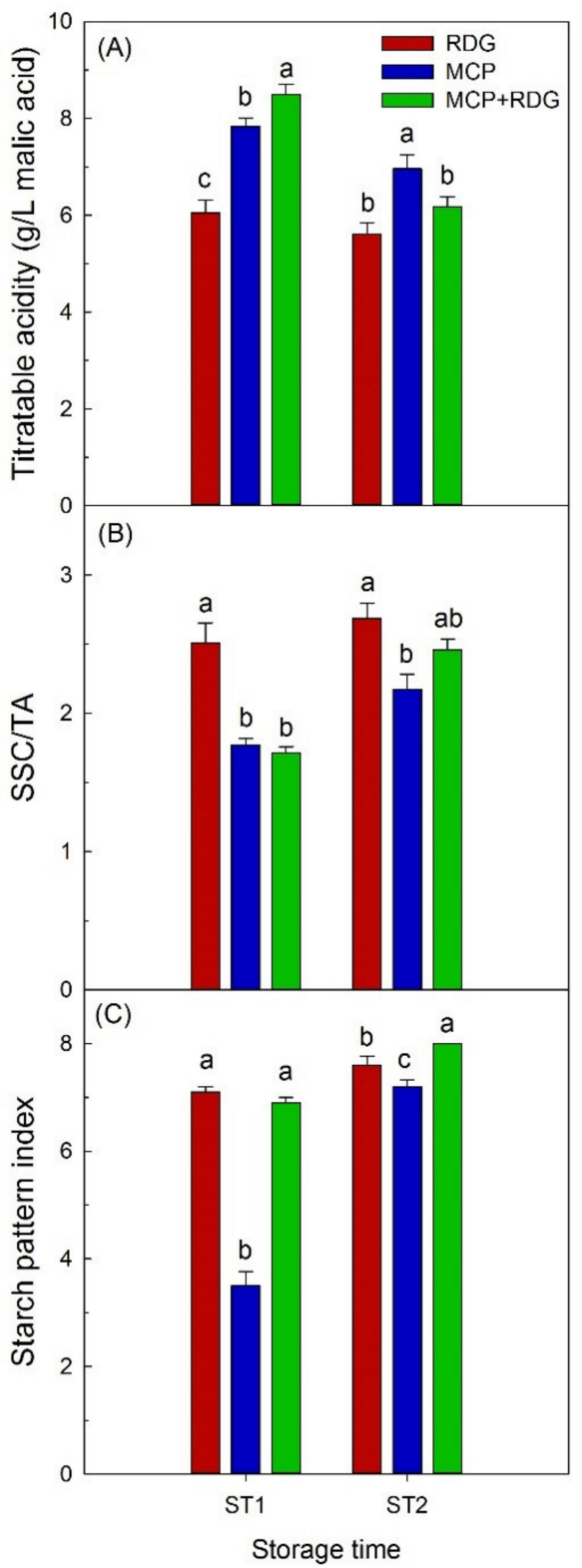

Figure 2. Titratable acidity (A), the SSC/TA (B) and starch pattern index (C) measured at two storage times (ST1 and ST2) for apples exposed to the three postharvest management treatments, RDG (standard reddening process), $\mathrm{MCP}$ (apples treated with 1-MCP, without the reddening process) and MCP + RDG (apples treated with 1-MCP and with the reddening process). For each sampling time, different letters indicate a statistically different value $(p \leq 0.05)$.

\subsection{Consumer Sensory Tests}

The storage time did not alter the overall liking of the apples, and the main effect of the MCP + RDG treatment was a significant increase in this parameter (Table 3). Nonetheless, there was a significant factor interaction, because statistically different scores among treatments were present at ST2 (Figure 3A). The postharvest treatment significantly affected 
all the other attributes than the intensity of the aroma, which was not affected by the storage time (and neither by factor interactions).

Table 3. Effect postharvest management treatment $(\mathrm{T})$, storage time $(\mathrm{ST})$ and $\mathrm{S} \times \mathrm{T}$ interaction on apples attributes evaluated by a consumer test.

\begin{tabular}{|c|c|c|c|c|c|c|c|c|}
\hline $\begin{array}{l}\text { Source of } \\
\text { Variation }\end{array}$ & $\begin{array}{l}\text { Overall } \\
\text { Liking }\end{array}$ & Hardness & Crunchiness & Juiciness & Mealiness & $\begin{array}{l}\text { Sweet } \\
\text { Taste }\end{array}$ & $\begin{array}{l}\text { Sour } \\
\text { Taste }\end{array}$ & $\begin{array}{c}\text { Aroma } \\
\text { Intensity }\end{array}$ \\
\hline \multicolumn{9}{|l|}{$\begin{array}{l}\text { Treatment } \\
\text { (T) }\end{array}$} \\
\hline RGD & $6.0 \pm 0.1 b$ & $4.1 \pm 0.1 c$ & $4.4 \pm 0.1 b$ & $5.4 \pm 0.1 \mathrm{~b}$ & $5.3 \pm 0.2 \mathrm{a}$ & $5.8 \pm 0.1 a$ & $3.6 \pm 0.1 b$ & $5.5 \pm 0.1$ \\
\hline MCP & $5.9 \pm 0.1 b$ & $6.6 \pm 0.1 \mathrm{a}$ & $6.8 \pm 0.1 \mathrm{a}$ & $5.8 \pm 0.1 \mathrm{ab}$ & $3.1 \pm 0.1 b$ & $4.5 \pm 0.1 \mathrm{c}$ & $5.3 \pm 0.2 \mathrm{a}$ & $5.1 \pm 0.1$ \\
\hline $\mathrm{MCP}+\mathrm{RDG}$ & $6.6 \pm 0.1 \mathrm{a}$ & $6.2 \pm 0.1 b$ & $6.6 \pm 0.1 \mathrm{a}$ & $6.0 \pm 0.2 \mathrm{a}$ & $3.0 \pm 0.2 b$ & $5.0 \pm 0.2 b$ & $5.0 \pm 0.2 \mathrm{a}$ & $5.6 \pm 0.1$ \\
\hline $\begin{array}{l}\text { Significance } \\
\text { Storage }\end{array}$ & $* * *$ & $* * *$ & $* * *$ & * & $* * *$ & $* * *$ & $* * *$ & $n . s$. \\
\hline \\
\hline ST1 & $6.3 \pm 0.1$ & $5.9 \pm 0.1 \mathrm{a}$ & $6.2 \pm 0.1 \mathrm{a}$ & $5.8 \pm 0.1$ & $3.7 \pm 0.1$ & $5.0 \pm 0.1$ & $4.7 \pm 0.1$ & $5.5 \pm 0.1$ \\
\hline ST2 & $6.1 \pm 0.1$ & $5.2 \pm 0.2 b$ & $5.5 \pm 0.1 b$ & $5.7 \pm 0.1$ & $3.9 \pm 0.2$ & $5.2 \pm 0.1$ & $4.5 \pm 0.1$ & $5.3 \pm 0.1$ \\
\hline Significance & n.s. & $* * *$ & $* * *$ & $n . s$. & $n . s$. & $n . s$. & $n . s$. & $n . s$. \\
\hline $\mathrm{T} \times \mathrm{ST}$ & ** & ** & $n . s$. & $n . s$. & * & $n . s$. & $n . s$. & $n . s$. \\
\hline
\end{tabular}

$n$. s. ${ }^{*},{ }^{* *}, * * *$ non-significant or significant at $p \leq 0.05,0.01$ and 0.001 , respectively.

The consumer test indicated that the storage time decreased the hardness of the fruits (Table 3). This attribute was ranked at the highest level in the MCP apples, followed by the MCP + RDG apples, while the score for RDG apples was more distant. While hardness was higher for apples that were exposed to MCP at ST1, the addition of the melaio stage of the MCP + RDG associated to an intermediate hardness at ST2 (Figure 3B).

Crunchiness, similar to hardness, decreased at ST2, with higher values in $\mathrm{MCP}$ and $\mathrm{MCP}+\mathrm{RDG}$ and RDG apples scoring substantially lower values (-35\%) (Table 3). Juiciness was not affected by the storage time, but there was a significant difference only between the RDG (lowest value) and the MCP + RDG treatment. On the other hand, mealiness, sweet taste and sour taste were not affected by the storage, but the postharvest treatment had a highly significant effect. In particular, the presence of the MCP in the postharvest management is associated with a significant reduction of the mealiness, but at the same time, fruits are judged soured and less sweet (Table 3 and Figure 3C). As also noted for hardness, the addition of a stage in melaio of the apples exposed to MCP caused a significant difference only at the ST2. Finally, in terms of flavor, the MCP-RDG apples were ranked in the middle of the other two treatments regarding the "sweet taste" attribute, while reddening following MCP-yielded apples with similar "sour taste". Overall, the presence of the MCP treatment in postharvest (i.e., the MCP and the MCP + RDG management procedures) associated with an improved texture considering juiciness, firmness and mealiness. On the other hand, RGD apples were evaluated sweeter and less sour, while the perception of the aroma intensity was not affected by the postharvest management. The MCP + RGD treatment provided the higher overall liking score, guaranteeing a good texture and differing from the $\mathrm{MCP}$ mainly because of a higher perceived sweetness. 


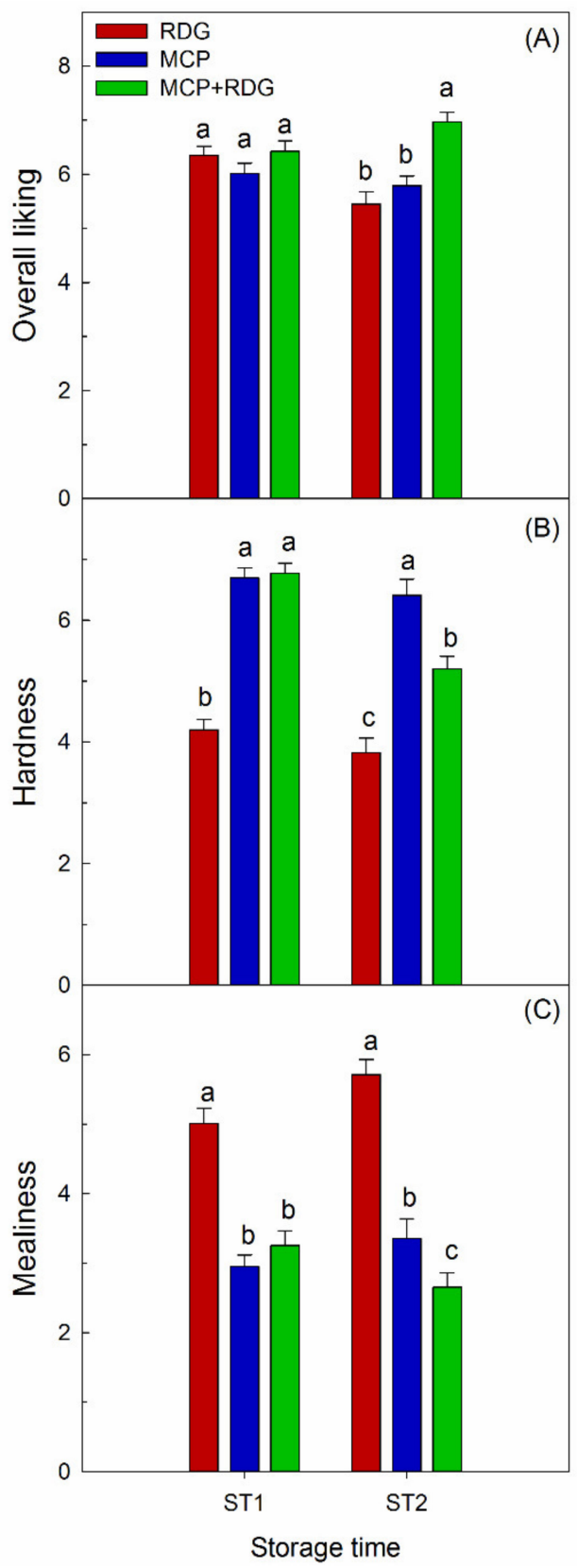

Figure 3. Consumer's overall liking ( $1=$ extremely dislike, $9=$ extremely like, with $5=$ neither like nor dislike) (A), hardness ( $1=$ very low, $9=$ very high, with $5=$ medium) $(\mathbf{B})$ and mealiness ( 1 = very low, 9 = very high, with $5=$ medium) (C) evaluated at two storage times (ST1 and ST2) for apples exposed to the three postharvest management treatments, RDG (standard reddening process), $\mathrm{MCP}$ (apples treated with 1-MCP, without the reddening process) and MCP + RDG (apples treated with 1-MCP and with the reddening process). For each sampling time, different letters indicate a statistically different value $(p \leq 0.05)$.

\subsection{Correlation Analysis}

We performed a correlation analysis between the morphometric variables and the sensory attributes assessed by the consumers (Figure 4). The variables that were mostly correlated with others were "Firmness" and "Sour taste" (both with six significant correlations). The former was correlated with textural attributes ("Hardness", "Crunchiness" and "Mealiness") but also with "Sour taste". As expected, SPI was positively correlated with SSC, while the quantity of TA was negatively correlated with the SSC/TA ratio. It is remarkable that the linear correlation between the overall liking and both the sensory 
features and the measured fruit traits was always low (and not significant). Moreover, the measured fruits traits besides "Firmness" (i.e., SSC, pH, TA, SSC/TA and SPI) were in general also poorly correlated with sensory variables. Specifically, the SPI was the measured fruit trait that, besides its expected connection with SSC, did not linearly correlate with any other variable.

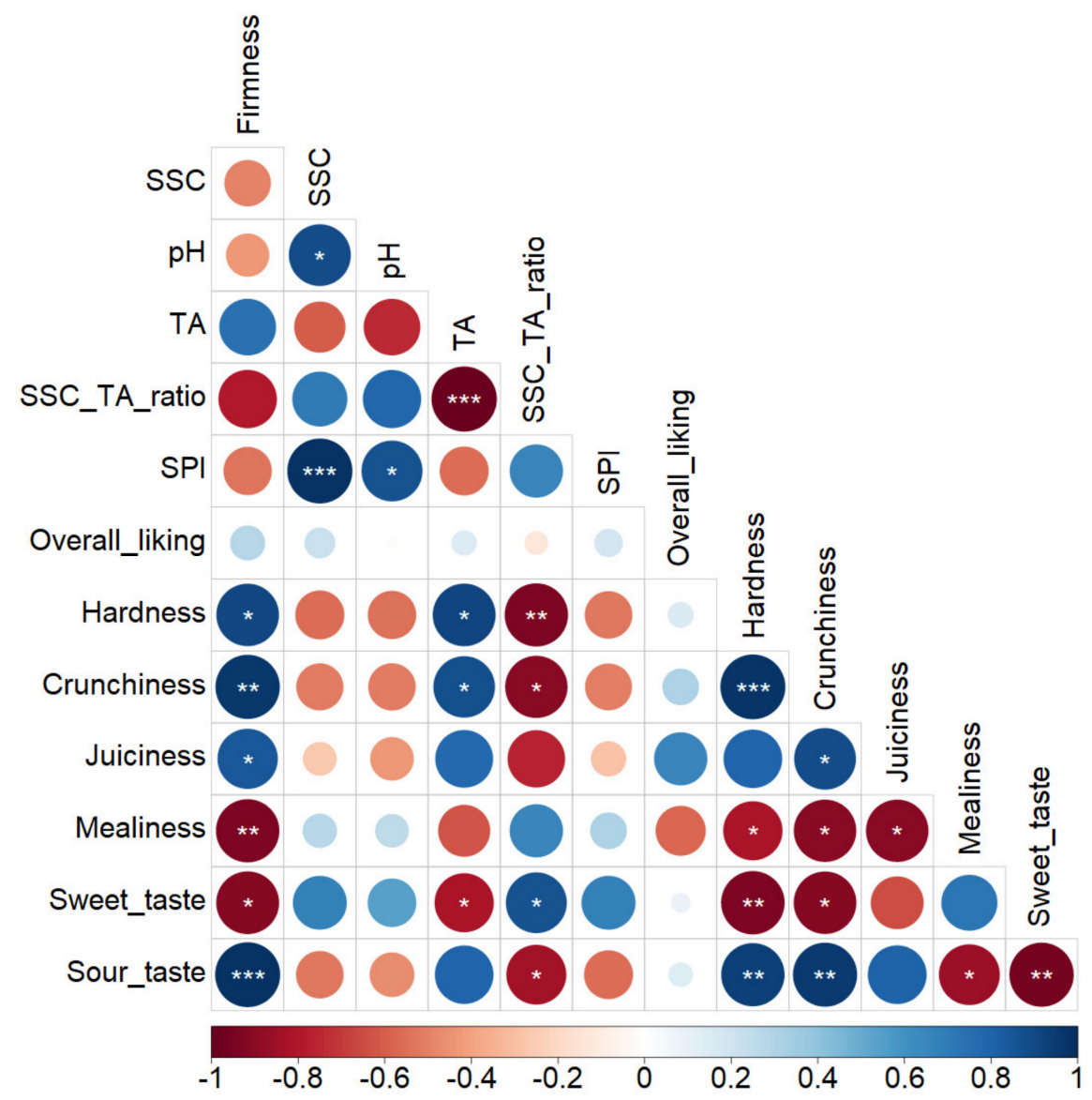

Figure 4. Correlogram representing the Pearson correlation coefficient matrix between apple composition and sensorial attributes. Asterisks indicate the significance of the Pearson correlation coefficient $\left({ }^{*}, * * * * *\right.$ correspond to $p \leq 0.05,0.01$ and 0.001 , respectively). Colors indicate different values of the correlation coefficient according to the scale bar reported at the bottom. The size of the circle is proportional to the correlation coefficients.

\section{Discussion}

Apple skin color, absence of defects, taste, aroma, crispness, juiciness, sweetness, mouthfeel and texture are considered to be the main sensorial attributes driving consumer choice [20,31-33]. The consumer perception of a typical food is crucial to preserve crop landraces on-farm, and therefore, interventions to modify a traditional production system should always consider these issues. Under this perspective, the current work illustrates how the 1-MCP treatment and the traditional melaio reddening can positively impact postharvest performance and fruit sensorial attributes of "Melannurca Campana" apples.

Regardless of the treatment, skin color yellowed (as indicated by the increase in the Hue angle) and became less bright during storage [34]. The yellowing of the apple skin during cold storage was reported to be correlated to both an increase in carotenoids and a decrease in chlorophylls in the skin [35]. Chlorophyll degradation and carotenoid biosynthesis may account, respectively, for the increase in the $\mathrm{a}^{*}$ and $\mathrm{b}^{*}$ values that caused the increase in the Hue angle we measured during the storage in all the treatments. Interestingly, MCP apples were more yellow than in RDG and MCP + RDG treatments 
throughout the storage, whereas no difference in the $b^{*}$ value was found between RDG and MCP + RDG. This result suggests that the treatment with 1-MCP applied right after harvest did not worsen the reddening capacity of the traditional melaio practice in terms of color properties. Taste and acidity are considered key gustatory attributes driving consumer preference for apples [36,37]. As expected, titratable acidity diminished with the storage time irrespective of the treatment. This trend is due to organic acid degradation through respiration [10]. The presence of MCP in the postharvest management guaranteed a higher TA value compared to the RGD treatments. Previous works indicated that 1-MCP inhibits loss of TA and firmness during storage [38-41]. Apple firmness is one of the most important criteria concerning the eating quality of apples [42], and the postharvest phase and, in particular, the storage condition, have large effects on maintaining flesh firmness of commercial apples [43]. In our case, firmness was well preserved during storage, yet its variation among treatments was consistent with differences in TA. In both MCP and $\mathrm{MCP}+\mathrm{RDG}$ treatments, the application of 1-MCP increased flesh firmness. The observed differences in TA and firmness can, therefore, be explained with an inhibition of the maturation process that occurs in melaio when apples are MCP-treated before reddening. However, it is noteworthy that the SPI, similarly to the SSC content, was higher for apples that underwent a stage in melaio, regardless of the presence of a 1-MCP treatment. An increase in SSC is typically associated with starch degradation during postharvest [44]. Specifically, the SPI index is inversely correlated to the starch (mainly amylose) content in apples [30]. Overall, the responses suggest that the stimulating effect of open-field reddening on apples combined with the preventive application of 1-MCP allows us to untangle color evolution, starch degradation and reduction in titratable acidity during cold storage.

The efficacy of 1-MCP in preserving fruit firmness in MCP + RDG apples is important to increase "Annurca" postharvest quality in terms of long-term marketability and influence on consumer perception. Interestingly, the MCP + RDG treatment significantly increased the "overall liking" score, while the other two postharvest management marked equivalent evaluations. Differences due to the storage time were not evident. This is not surprising considering that the "Melannurca Campana" apples have been selected and are routinely managed to be consumed after a reddening process away from the tree. Nonetheless, it was not possible to correlate the "overall liking" with specific traits and attributes. One reason is that some differences perceived sensorially are not always adequately predicted by instrumental measures [24,25]. The perception of pulp firmness was the attribute that mostly correlated with the other consumer responses, yet a significant correlation between firmness and overall liking was not found. This suggests that the collinearity between the measured variables and the consumer appreciation may be reduced, and more complex relations should be explored by, for instance, regression analysis through different stages of maturation. The overall increase in consumer appreciation of the MCP + RDG apples may derive from the combinations of different influences. A cross-national study on apple consumer acceptance found that the best accepted varieties in many European countries were characterized by high firmness, high SSC and an average or lower than average TA (corresponding to $5.2 \mathrm{~g} / \mathrm{L}$ of malic acid in the cited study) [45]. In our study, these parameters were positively affected by the 1-MCP. It should be also added that pulp firmness is not sufficient to fully explain the textural properties of apple fruits as perceived by consumers [46]. Other properties found to be positively correlated with consumers liking in apples are, for instance, juiciness and crunchiness [31]. The treatment with 1-MCP positively impacted crunchiness and, at a lesser extent, juiciness. Conversely, mealiness is almost universally considered a negative attribute of texture, combining the sensation of a desegregated tissue with that of lack of juiciness [47]. Mealiness tends to be more frequent in stored apples [37], but the storage time did not influence this parameter, confirming the intrinsic suitability for long-term storage of the "Annurca" apples. Moreover, the decreased pulp mealiness associated to the 1-MCP treatment is particularly encouraging, because mealiness represents a major issue for the marketability of cold-stored "Annurca" apples [9]. 


\section{Conclusions}

This work demonstrated that 1-MCP technology can be integrated into a traditional postharvest process in open field to improve fruit quality and, potentially, to extend the shelf life through an increased firmness. This is feasible because the "Melannurca Campana" PGI protocol bans only the application of phytosanitary products during the reddening in melaio [26]. A single application of 1-MCP to the fruit of a short-stemmed apple landrace suffering from premature fruit drop was adequate to prevent excessive loss of pulp firmness and to slow the decay of the fruit composition in terms of TA and SSC/TA. Although protocols need to be further developed and adapted, we demonstrate that the 1-MCP tool could be incorporated into the "Melannurca Campana" reddening process in small farms without the need for additional facilities (beyond a cold-storage room). In particular, in melaio treatment of the 'Annurca' apples with 1-MCP before the reddening has the potential to allow the marketing of fruits with a longer shelf-life without diminishing the quality characteristics and consumer preferences. These are essential traits to favor the diffusion of the PGI "Melannurca Campana" outside the currently reached market areas and fruit marketing season.

Supplementary Materials: The following are available online at https://www.mdpi.com/article/10 .3390/agronomy11061056/s1. Figure S1: an example of the fruits at ST2.

Author Contributions: Conceptualization, B.B.; methodology, B.B., P.S., A.M. and M.T.; formal analysis, P.S., A.M., M.T., M.T.L., G.C. and B.B.; investigation, P.S., A.M., M.I., M.T. and B.B.; writing—original draft preparation, M.T.L. and A.M.; writing—review and editing, B.B., G.C., P.P., Y.R. and M.C.K.; supervision, B.B. All authors have read and agreed to the published version of the manuscript.

Funding: This research received no external funding.

Data Availability Statement: The data presented in this study are contained within the article or supplementary material. Raw data are available on request from the corresponding author.

Acknowledgments: We thank the whole staff of Giaccio Frutta and, in particular, Giuseppe Giaccio for granting access to the farm facilities without undue reservations.

Conflicts of Interest: The authors declare no conflict of interest.

\section{References}

1. FAOSTAT. Available online: http://www.fao.org/faostat/en (accessed on 1 March 2021).

2. D'Abrosca, B.; Fiorentino, A.; Monaco, P.; Oriano, P.; Pacifico, S. Annurcoic acid: A new antioxidant ursane triterpene from fruits of cv. Annurca apple. Food Chem. 2006, 98, 285-290. [CrossRef]

3. Guerra, W. Annurca una specialita campana. Frutta e Vite 2020.

4. Mari, A.; Tedesco, I.; Nappo, A.; Russo, G.L.; Malorni, A.; Carbone, V. Phenolic compound characterisation and antiproliferative activity of "Annurca" apple, a southern Italian cultivar. Food Chem. 2010, 123, 157-164. [CrossRef]

5. Cefarelli, G.; D’Abrosca, B.; Fiorentino, A.; Izzo, A.; Mastellone, C.; Pacifico, S.; Piscopo, V. Free-Radical-Scavenging and Antioxidant Activities of Secondary Metabolites from Reddened Cv. Annurca Apple Fruits. J. Agric. Food Chem. 2006, 54, 803-809. [CrossRef]

6. Balogh, P.; Békési, D.; Gorton, M.; Popp, J.; Lengyel, P. Consumer willingness to pay for traditional food product. Food Policy 2016, 61, 176-184. [CrossRef]

7. Lo Scalzo, R.; Forni, E.; Lupi, D.; Giudetti, G.; Testoni, A. Changes of pectic composition of "Annurca" apple fruit after storage. Food Chem. 2005, 93, 521-530. [CrossRef]

8. Lintas, C.; Paoletti, F.; Cappelloni, M.; Gambelli, L.; Monastra, F.; Ponziani, G. Agronomic, nutritional and texture evaluation of "Annurca" apple clones. Adv. Hortic. Sci. 1993, 7, 165-168.

9. Scalzo, R.L.; Testoni, A.; Genna, A. 'Annurca' apple fruit, a southern Italy apple cultivar: Textural properties and aroma composition. Food Chem. 2001, 73, 333-343. [CrossRef]

10. Brizzolara, S.; Manganaris, G.A.; Fotopoulos, V.; Watkins, C.B.; Tonutti, P. Primary Metabolism in Fresh Fruits During Storage. Front. Plant Sci. 2020, 11, 80. [CrossRef]

11. Blankenship, S.M.; Dole, J.M. 1-Methylcyclopropene: A review. Postharvest Biol. Technol. 2003, 28, 1-25. [CrossRef]

12. Hu, B.; Sun, D.-W.; Pu, H.; Wei, Q. Recent advances in detecting and regulating ethylene concentrations for shelf-life extension and maturity control of fruit: A review. Trends Food Sci. Technol. 2019, 91, 66-82. [CrossRef] 
13. Sisler, E.C.; Serek, M. Inhibitors of ethylene responses in plants at the receptor level: Recent developments. Physiol. Plant. 1997, 100, 577-582. [CrossRef]

14. Fan, X.; Mattheis, J.P. Impact of 1-methylcyclopropene and methyl jasmonate on apple volatile production. J. Agric. Food Chem. 1999, 47, 2847-2853. [CrossRef]

15. Dong, L.; Lurie, S.; Zhou, H.-W. Effect of 1-methylcyclopropene on ripening of 'Canino' apricots and 'Royal Zee' plums. Postharvest Biol. Technol. 2002, 24, 135-145. [CrossRef]

16. Gwanpua, S.G.; Verlinden, B.E.; Hertog, M.L.; Nicolai, B.M.; Geeraerd, A.H. A mechanistic modelling approach to understand 1-MCP inhibition of ethylene action and quality changes during ripening of apples. J. Sci. Food Agric. 2017, 97, 3802-3813. [CrossRef]

17. Lee, J.; Mattheis, J.P.; Rudell, D.R. Storage Temperature and 1-Methylcyclopropene Treatment Affect Storage Disorders and Physiological Attributes of ‘Royal Gala' Apples. HortScience 2016, 51, 84-93. [CrossRef]

18. Watkins, C.B.; Nock, J.F. Rapid 1-methylcyclopropene (1-MCP) treatment and delayed controlled atmosphere storage of apples. Postharvest Biol. Technol. 2012, 69, 24-31. [CrossRef]

19. Watkins, C.B.; Nock, J.F.; Whitaker, B.D. Responses of early, mid and late season apple cultivars to postharvest application of 1-methylcyclopropene (1-MCP) under air and controlled atmosphere storage conditions. Postharvest Biol. Technol. 2000, 19, 17-32. [CrossRef]

20. Falagán, N.; A Terry, L. 1-Methylcyclopropene maintains postharvest quality in Norwegian apple fruit. Food Sci. Technol. Int. 2019, 26, 420-429. [CrossRef]

21. Zhang, J.; Ma, Y.; Dong, C.; Terry, L.A.; Watkins, C.B.; Yu, Z.; Cheng, Z.-M. (Max) Meta-analysis of the effects of 1methylcyclopropene (1-MCP) treatment on climacteric fruit ripening. Hortic. Res. 2020, 7, 1-16. [CrossRef]

22. Tsantili, E.; Gapper, N.E.; Arquiza, J.M.R.A.; Whitaker, B.D.; Watkins, C.B. Ethylene and $\alpha$-Farnesene Metabolism in Green and Red Skin of Three Apple Cultivars in Response to 1-Methylcyclopropene (1-MCP) Treatment. J. Agric. Food Chem. 2007, 55, 5267-5276. [CrossRef]

23. Melchiade, D.; Foroni, I.; Corrado, G.; Santangelo, I.; Rao, R. Authentication of the 'Annurca' Apple in Agro-food Chain by Amplification of Microsatellite Loci. Food Biotechnol. 2007, 21, 33-43. [CrossRef]

24. Harker, F.; Maindonald, J.; Murray, S.; Gunson, A.; Hallett, I.; Walker, S. Sensory interpretation of instrumental measurements 1: Texture of apple fruit. Postharvest Biol. Technol. 2002, 24, 225-239. [CrossRef]

25. Harker, F.; Marsh, K.; Young, H.; Murray, S.; Gunson, A.; Walker, S. Sensory interpretation of instrumental measurements 2: Sweet and acid taste of apple fruit. Postharvest Biol. Technol. 2002, 24, 241-250. [CrossRef]

26. CEE Rule, nr. 417/2006 Europe Council of 14/07/1992. Disciplinare di produzione Disciplinare di produzione dell'Indicazione Geografica Protetta "Melannurca Campana". Gazzetta Ufficiale Italiana, 7 April 2004; n.82.

27. Murakami, P.F.; Turner, M.R.; Berg, A.K.V.D.; Schaberg, P.G. An Instructional Guide for Leaf Color Analysis Using Digital Imaging Software; USDA Forest Service: Delaware, OH, USA, 2005; Volume 327, p. 37. [CrossRef]

28. Schanda, J. (Ed.) Colorimetry; John Wiley \& Sons: Hoboken, NJ, USA, 2007; Volume 4, p. 408. ISBN 9780470049044.

29. Blanpied, G.D.; Silsby, K.J. Predicting Harvest Date Windows for Apples; Cornell Cooperative Extension Publications: Riverhead, NY, USA, 1992.

30. Doerflinger, F.C.; Miller, W.B.; Nock, J.F.; Watkins, C.B. Relationships between starch pattern indices and starch concentrations in four apple cultivars. Postharvest Biol. Technol. 2015, 110, 86-95. [CrossRef]

31. Péneau, S.; Hoehn, E.; Roth, H.-R.; Escher, F.; Nuessli, J. Importance and consumer perception of freshness of apples. Food Qual. Prefer. 2006, 17, 9-19. [CrossRef]

32. İglesias, I.; Alegre, S. The effect of anti-hail nets on fruit protection, radiation, temperature, quality and probability of Mondial Gala apples. J. Appl. Hortic. 2006, 8, 91-100. [CrossRef]

33. Iglesias, I.; Echeverría, G.; Soria, Y. Differences in fruit colour development, anthocyanin content, fruit quality and consumer acceptability of eight 'Gala' apple strains. Sci. Hortic. 2008, 119, 32-40. [CrossRef]

34. Dobrzański, B.J.; Rybczyński, R. Colour change of apple as a result of storage, shelf-life, and bruising. Int. Agrophysics 2002, 16, 261-268.

35. Reay, P.F. The effects of maturity on colour and concentration of pigments in the blush and shaded sides of 'Gala' apple fruit during cool storage. J. Hortic. Sci. Biotechnol. 1998, 73, 841-845. [CrossRef]

36. Daillant-Spinnler, B.; MacFie, H.; Beyts, P.; Hedderley, D. Relationships between perceived sensory properties and major preference directions of 12 varieties of apples from the Southern Hemisphere. Food Qual. Prefer. 1996, 7, 113-126. [CrossRef]

37. Jaeger, S.R.; Andani, Z.; Wakeling, I.N.; MacFie, H.J. Consumer preferences for fresh and aged apples: A cross-cultural comparison. Food Qual. Prefer. 1998, 9, 355-366. [CrossRef]

38. Kolniak-Ostek, J.; Wojdyło, A.; Markowski, J.; Siucińska, K. 1-Methylcyclopropene postharvest treatment and their effect on apple quality during long-term storage time. Eur. Food Res. Technol. 2014, 239, 603-612. [CrossRef]

39. Özkaya, O.; Dündar, Ö. Influence of 1-methylcyclopropene (1-MCP) on "Fuji" apple quality during long-term storage. J. Food Agric. Environ. 2009, 7, 146-148.

40. Dauny, P.T.; Joyce, D.C. 1-MCP Improves Storability of 'Queen Cox' and 'Bramley' Apple Fruit. HortScience 2002, 37, 1082-1085. [CrossRef] 
41. Bulens, I.; Van De Poel, B.; Hertog, M.; De Proft, M.; Geeraerd, A.; Nicolai, B. Influence of harvest time and 1-MCP application on postharvest ripening and ethylene biosynthesis of 'Jonagold' apple. Postharvest Biol. Technol. 2012, 72, 11-19. [CrossRef]

42. Hoehn, E.; Gasser, F.; Guggenbühl, B.; Künsch, U. Efficacy of instrumental measurements for determination of minimum requirements of firmness, soluble solids, and acidity of several apple varieties in comparison to consumer expectations. Postharvest Biol. Technol. 2003, 27, 27-37. [CrossRef]

43. DeEll, J.R.; Khanizadeh, S.; Saad, F.; Ferree, D.C. Factors affecting apple fruit firmness-A review. J. Am. Pomol. Soc. 2001, $55,8-26$.

44. Duque, P.; Barreiro, M.G.; Arrabaça, J.D. Respiratory metabolism during cold storage of apple fruit. I. Sucrose metabolism and glycolysis. Physiol. Plant. 1999, 107, 14-23. [CrossRef]

45. Bonany, J.; Buehler, A.; Carbó, J.; Codarin, S.; Donati, F.; Echeverria, G.; Egger, S.; Guerra, W.; Hilaire, C.; Höller, I.; et al. Consumer eating quality acceptance of new apple varieties in different European countries. Food Qual. Prefer. 2013, 30, 250-259. [CrossRef]

46. Peneau, S.; Brockhoff, P.B.; Hoehn, E.; Escher, F.; Nuessli, J. Relating Consumer Evaluation of Apple freshness to Sensory and Physico-Chemical Measurements. J. Sens. Stud. 2007, 22, 313-335. [CrossRef]

47. Barreiro, P.; Ortiz, C.; Ruiz-Altisent, M.; Schotte, S.; Andani, Z.; Wakeling, I.; Beyt, P.K. Comparison between Sensory and Instrumental Measurements for Mealiness Assessment in Apples-A Collaborative Test. J. Texture Stud. 1998, 29, 509-525. [CrossRef] 